\title{
Fabrication of temperature sensor based on copper oxide nanowires grown on titanium coated glass substrate
}

\author{
Ali A. Aluubouri, Abdulqader D. Faisal**, WafaA K. Khalef \\ University of Technology, Applied Science Department, Baghdad, Iraq
}

\begin{abstract}
Single phase, adherent films of copper oxide nanowires (CuO NWs) were successfully grown on a glass substrate. Titanium nanofilm was pre-coated on the glass substrate to assist the growth of a layer adherent to the substrate. The copper film of $1.5 \mu \mathrm{m}$ thickness was deposited via physical vapor deposition technique followed by thermal oxidation in air at various temperatures for $4 \mathrm{~h}$. The product was characterized by X-ray diffraction (XRD), scanning electron microscopy (SEM), ultraviolet-visible (UV-Vis) and Fourier transformation infrared (FT-IR) spectroscopy to find the crystal structure, morphology, phases, and optical properties of the deposited films. The CuO NWs film with $60 \%$ transmittance at wavelengths greater than $800 \mathrm{~nm}$ was obtained. It can be used as an infrared thermal imaging filter and in optoelectronic devices. The fabricated temperature sensor exhibited high sensitivity in the temperature range of $20^{\circ} \mathrm{C}$ to $180{ }^{\circ} \mathrm{C}$.
\end{abstract}

Keywords: nanowires; temperature sensor; energy gap; activation energy; sensitivity

\section{Introduction}

$\mathrm{CuO}$ (cupric oxide) and $\mathrm{Cu}_{2} \mathrm{O}$ (cuprous oxide) are two important transition metal oxides. They are p-type semiconductors [1] with experimentally established band gaps in the range of $1.1 \mathrm{eV}$ to $1.7 \mathrm{eV}$ and $1.8 \mathrm{eV}$ to $2.5 \mathrm{eV}$ for $\mathrm{CuO}$ and $\mathrm{Cu}_{2} \mathrm{O}$, respectively [2]. $\mathrm{CuO}$ has a monoclinic structure [3] and $\mathrm{Cu}_{2} \mathrm{O}$ is characterized by a cubic structure [4] and black color. Copper oxides are suitable for many promising applications, including light emitting diode (LED) [5], field emission lighting [6], catalysis [7], electrode material for lithium ion batteries [8], gas sensors [9], solar cells [10], charge storage material in supercapacitors [11], transistors [12], high critical temperature superconductors [13], photovoltaic materials [14], humidity and temperature sensors [15-18]. Recently, nanostructures of metaloxide, such as nanowire [19], nanoparticles [20], nanospheres [21], nanobelts [22], nanoneedles [23], nanoleaves [24], nanowhiskers [25], nanosheets [26], nanoribbons [27], have gained a great attention due to their distinctive

*E-mail: abdulf330@gmail.com and novel properties, different from conventional bulk and thin film materials, for new potential applications. Many methods have been developed to synthesize $\mathrm{CuO}$ nanowires or nanorods including sonochemical [28], electrochemical [29], sol-gel [30], spray pyrolysis [31], sputtering [32], microwave irradiation [33], hydrothermal [34], template-assisted synthesis [35], pulsed laser deposition [36], successive ionic layer adsorption and reaction (SILAR) [37], glow discharge [38], and thermal oxidation of copper foil [39]. However, all these methods, either require high temperatures, sophisticated instrumentation, inert atmosphere, or long reaction time. Among these methods, thermal oxidation of $\mathrm{Cu}$ in air represents low-cost and long-time method realized at moderate temperature. The formation of copper oxide nanowires ( $\mathrm{CuO} \mathrm{NWs}$ ) by direct thermal oxidation of metals has been recently given considerable attention due to its extreme simplicity and large-scale growth capability [40]. Comparing the $\mathrm{CuO}$ NWs prepared by thermal oxidation to the ones prepared via solution-based routes, the first technique produces nanowires with higher crystallinity and higher aspect ratios [41]. The thermal oxidation technique can be applied to fabricate nanowires that are 
of low-cost and high quality. The growth conditions can be controlled by varying temperature and time. In the present work, we have studied the influence of oxidation temperature on structure, morphology, optical and electrical properties of $\mathrm{CuO}$ films produced by thermal oxidation technique and the reliability of those films in temperature sensor fabrications.

\section{Experimental}

\subsection{Sample preparation}

High purity $(99.99 \%)$ and small size copper rods $(1.5 \mathrm{~cm}$ in length $\times 0.1 \mathrm{~cm}$ in diameter $)$ were used as a source material for the film evaporation. This material was loaded into a tungsten boat and placed in a vacuum chamber for physical vapor deposition (PVD). Glass slides were rinsed with deionized water, subjected to ultrasonication in acetone for $15 \mathrm{~min}$, and finally blow-dried with $\mathrm{N}_{2}$ gas. The titanium film was deposited onto the pre-cleaned glass substrates by RF-magnetron sputtering system (Torr International Inc., CRC600) using a $99.99 \%$ pure titanium target $(5 \mathrm{~cm}$ in diameter and $2 \mathrm{~mm}$ thick). The base pressure in the deposition chamber was $6.66 \times 10^{-2} \mathrm{~Pa}$ and the sputtering was carried out in an argon atmosphere of $30 \mathrm{sccm}$ with RF power of $100 \mathrm{~W}$. The film thickness of $30 \mathrm{~nm}$ was measured via thickness monitor. The titanium layer was coated before $\mathrm{Cu}$ deposition to improve adhesion between the copper layer and the glass substrate. The copper film deposition was carried out at room temperature in a chamber pre-evacuated to a pressure of $2 \mathrm{~Pa}$. The film thickness of $1.5 \mu \mathrm{m}$ was measured using the weight method. The oxidation experiments were carried out at atmospheric pressure at different temperatures $\left(400{ }^{\circ} \mathrm{C}\right.$ and $\left.500{ }^{\circ} \mathrm{C}\right)$ for $4 \mathrm{~h}$ in a horizontal tube furnace.

\subsection{Apparatus}

The crystalline structure of the product was investigated using Shimadzu XRD-6000, diffractometer equipped with $\mathrm{CuK} \alpha$ radiation $(\lambda=1.5406 \AA)$. The study was carried out at a scanning speed of $5 \% \mathrm{~min}$ and $2 \theta$ ranged from $20^{\circ}$ to $70^{\circ}$. The morphology of the product was observed with a scanning electron microscope (SEM FEI Inspect S50). The optical transmittance of the $\mathrm{CuO}$ film was measured using Shimadzu UV-Vis spectrophotometer, model 2450. The electrical parameters i.e. resistance and current were measured using a multimeter Fluke 8846A and a digital electrometer (Keithley 616), respectively. The voltage was supplied by DC power supply (Harga UNI-T UTP3325TD). The temperature was measured by the homemade temperature controller with a thermocouple.

\section{Results and discussion}

\subsection{XRD analysis}

Fig. 1 shows XRD spectra of $\mathrm{CuO}$ NWs on a glass slide pre-coated with a $30 \mathrm{~nm}$ Ti sputtered film. The copper films on the glass substrates were oxidized at temperatures of $400{ }^{\circ} \mathrm{C}$ and $500{ }^{\circ} \mathrm{C}$ in air for $4 \mathrm{~h}$, and denoted as $\mathrm{S} 1$ and $\mathrm{S} 2$, respectively. The structure of the films was pure and there was no evidence of copper metal. The appearance of the peaks was attributed to the completely oxidized $\mathrm{CuO}$ phase. Furthermore, it was found that the strongest intensities of the peaks were observed for the $\mathrm{CuO}$ at $\left(\begin{array}{lll}1 & 1 & -1\end{array}\right)$ and $\left(\begin{array}{lll}1 & 1 & 1\end{array}\right)$ planes for both samples (S1 and S2). It shows the preferred

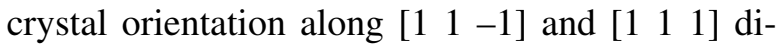
rections. Both XRD spectra shown in Fig. 1 were analyzed by a new version of the XRD match program. The samples can be indexed to the standard phase of the $\mathrm{CuO}$ monoclinic structure and belong to the Card No. 96-901-5823 (crystallography open data-COD).

\subsubsection{Crystal structure parameters calcula- tions}

The average crystallite size of the assynthesized $\mathrm{CuO}$ NWs was calculated according to the Debye-Scherrer formula:

$$
D=0.94 \lambda / \beta \cos \theta
$$

where $\mathrm{D}$ is the average crystallite size $[\mathrm{nm}], \lambda$ is the wavelength of $\mathrm{CuK} \alpha(0.15406 \mathrm{~nm}), \beta$ is the full width at half maximum intensity (FWHM) 

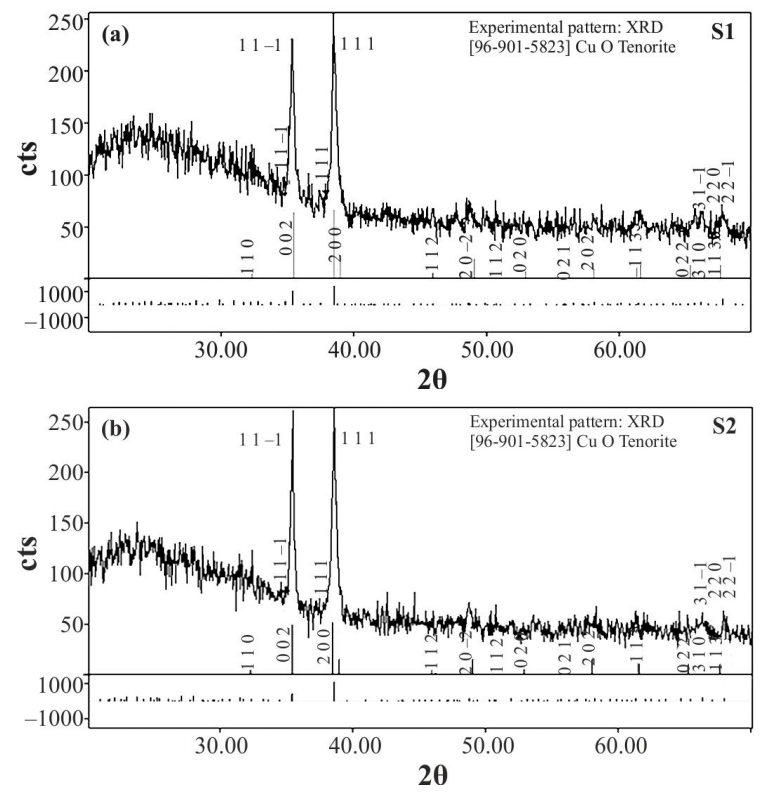

Fig. 1. XRD of CuO NWs on Ti-coated glass substrates oxidized at $400{ }^{\circ} \mathrm{C}(\mathrm{a})$, and at $500{ }^{\circ} \mathrm{C}$ (b) for $4 \mathrm{~h}$ in the air.

in radian and $\theta\left[^{\circ}\right]$ is the Bragg angle. According to the Debye-Scherer formula, the average crystallite sizes of the $\mathrm{CuO}$ nanostructures was calculated to be $24.5 \pm 8.1 \mathrm{~nm}$ and $28.9 \pm 6.99 \mathrm{~nm}$ for $\mathrm{S} 1$ and $\mathrm{S} 2$, respectively. These values reveal a fine nanocrystalline grain structure. The dislocation density $\delta$ is defined as a measure of line defects present in the crystal and it is inversely proportional to the crystallite size. It represents the amount of defects in the crystal. It was found from the relation [42]:

$$
\delta=1 / D^{2}\left(\text { Lines } / \mathrm{nm}^{2}\right)
$$

The calculated dislocation densities of $\mathrm{CuO}$ NWs for S1 and S2 are about $18.8 \pm 8.0 \times 10^{-4} / \mathrm{nm}^{2}$ and $13.6 \pm 5.8 \times 10^{-4} / \mathrm{nm}^{2}$, respectively. These values are given in Table 1 . The large size of the grains and the small value of the dislocation density is an indication of good crystallization [43].

\subsection{SEM analysis}

The morphology of the $\mathrm{CuO}$ nanostructures was analyzed via SEM. Fig. 2 shows the images of $\mathrm{CuO}$ nanowires grown on glass substrates at different oxidation temperatures, $400{ }^{\circ} \mathrm{C}(\mathrm{S} 1)$ and $500{ }^{\circ} \mathrm{C}$ (S2) for $4 \mathrm{~h}$ in the air. As can be seen from the top view, the nanowires have grown uniformly, smoothly and compactly. In addition, the nanowires are roughly aligned perpendicular to the substrate surface, when the oxidation temperature was increased from $400{ }^{\circ} \mathrm{C}$ to $500{ }^{\circ} \mathrm{C}$.

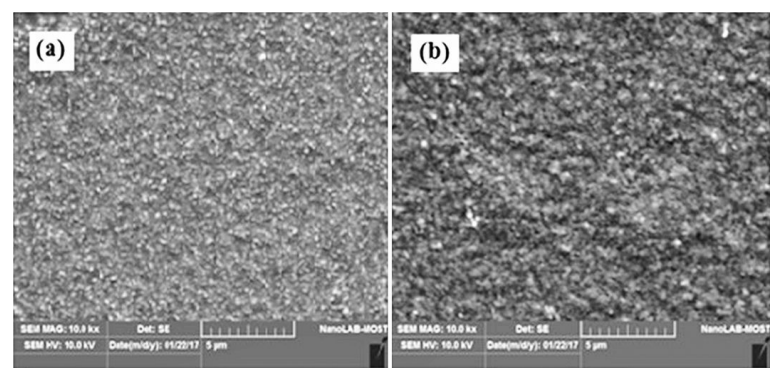

Fig. 2. SEM images of $\mathrm{CuO}$ NWs on Ti film sputtered on a glass slide, oxidized in air for $4 \mathrm{~h}$ at $400{ }^{\circ} \mathrm{C}$ (a), $500{ }^{\circ} \mathrm{C}(\mathrm{b})$.

\subsection{Optical properties of $\mathrm{CuO}$}

Fig. 3a and Fig. 3c show transmission spectra of the copper oxide nanowires on glass, prepared via oxidation of copper films at $400{ }^{\circ} \mathrm{C}$ and $500{ }^{\circ} \mathrm{C}$ in air for $4 \mathrm{~h}$. The optical transmissions of the $\mathrm{CuO}$ nanowire films observed in this study are about $50 \%$ and $70 \%$ for S1 (Fig. 3a) and S2 (Fig. 3c), respectively. It is clear that the optical transmittance values are located in the infrared region of the spectra at wavelength above $800 \mathrm{~nm}$ and increase with increasing wavelength. This property of the $\mathrm{CuO}$ nanowire films can be useful for different applications including an infrared (IR) filter in the infrared region and a solar cell in the UV-Vis region. The optical band gap $\mathrm{E}_{\mathrm{g}}$ is evaluated using Tauc plots $\alpha \mathrm{h} v=\left(\mathrm{h} v-\mathrm{E}_{\mathrm{g}}\right)^{\mathrm{n}}$, where hv is the incident photon energy and $\mathrm{n}$ is the exponent that determines the type of electronic transition causing the absorption, which can take the values $1 / 2,2 / 3,3 / 2$ and 2 . The best linear relationship has been obtained for $(\alpha h v)^{2}$ against hv plot, indicating that the optical band gap of these nanowires is due to a direct allowed transition. The calculated band gap energies of the $\mathrm{CuO}$ NWs for $\mathrm{S} 1$ and $\mathrm{S} 2$ are $1.6 \mathrm{eV}$ and $1.7 \mathrm{eV}$, respectively. These values are in good agreement with the literature data [44, 45]. 
Table 1. Crystal structure parameters calculated for $\mathrm{CuO}$ NWs oxidized at $400{ }^{\circ} \mathrm{C}(\mathrm{S} 1)$ and $500{ }^{\circ} \mathrm{C}(\mathrm{S} 2)$ in air for $4 \mathrm{~h}$.

\begin{tabular}{|c|c|c|c|c|c|}
\hline $\begin{array}{c}\text { Sample } \\
\text { No./oxidation } \\
\text { temp. }\left[{ }^{\circ} \mathrm{C}\right] \\
\end{array}$ & $2 \theta^{\circ}$ & $\begin{array}{l}\text { Reflection } \\
\text { plane }\end{array}$ & $\begin{array}{c}\text { Lattice } \\
\text { constant d } \\
{[\AA]} \\
\end{array}$ & $\begin{array}{l}\text { Crystallite size } \\
\text { Scherrer/D [nm] }\end{array}$ & $\begin{array}{l}\delta / \text { dislocation density } \\
{\left[\left(\text { lines } / \mathrm{nm}^{2}\right) \times 10^{-4}\right]}\end{array}$ \\
\hline \multirow{5}{*}{$\mathrm{S} 1 / 400$} & 32.4280 & $\left(\begin{array}{lll}1 & 1 & 0\end{array}\right)$ & 2.7687 & 36.8 & 7.4 \\
\hline & 35.4997 & $\left(\begin{array}{lll}1 & 1 & -1\end{array}\right)$ & 2.5267 & 22.0 & 20.7 \\
\hline & 38.6651 & $\left(\begin{array}{lll}1 & 1 & 1\end{array}\right)$ & 2.3268 & 20.5 & 20.7 \\
\hline & 48.8221 & $\left(\begin{array}{lll}2 & 0 & 2\end{array}\right)$ & 1.8639 & 19.5 & 26.3 \\
\hline & & & & $\mathrm{D}_{\mathrm{av} .}=24.5 \pm 8.1$ & $\delta_{\mathrm{av} .}=18.8 \pm 8.0$ \\
\hline \multirow{6}{*}{$\mathrm{S} 2 / 500$} & 32.3111 & $\left(\begin{array}{lll}1 & 1 & 0\end{array}\right)$ & 2.7684 & 38.3 & 06.8 \\
\hline & 35.3817 & $\left(\begin{array}{lll}1 & 1 & -1\end{array}\right)$ & 2.5349 & 26.5 & 14.2 \\
\hline & 38.5231 & $\left(\begin{array}{lll}1 & 1 & 1\end{array}\right)$ & 2.3351 & 22.8 & 19.2 \\
\hline & 38.9846 & $\left(\begin{array}{lll}2 & 0 & 0\end{array}\right)$ & 2.3085 & 34.0 & 08.6 \\
\hline & 48.7038 & $\left(\begin{array}{lll}2 & 0 & 2\end{array}\right)$ & 1.8681 & 22.7 & 19.4 \\
\hline & & & & $\mathrm{D}_{\mathrm{av} .}=28.9 \pm 6.99$ & $\delta_{\mathrm{av} .}=13.6 \pm 5.8$ \\
\hline
\end{tabular}
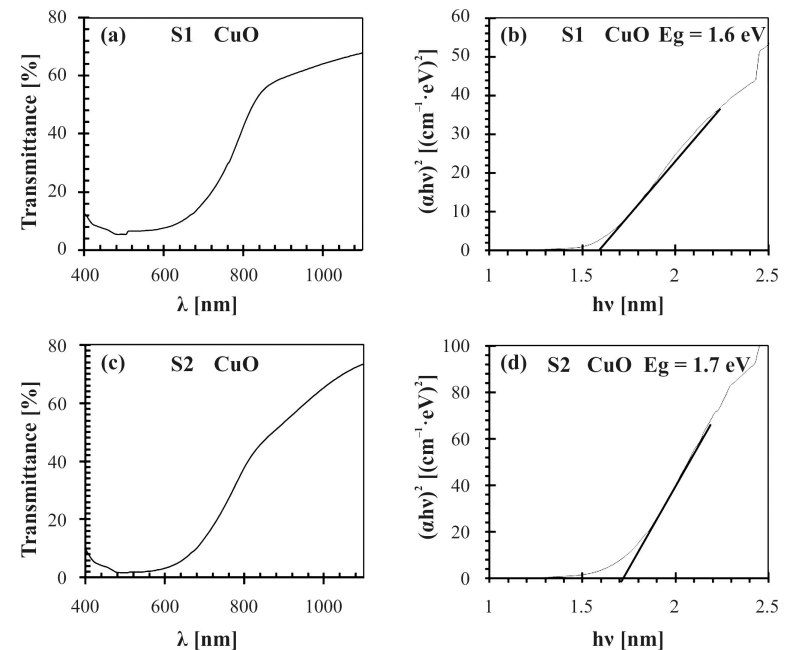

Fig. 3. Optical transmission spectra of $1.5 \mu \mathrm{m}$ thick $\mathrm{CuO}$ nanowire films on glass, oxidized at $400{ }^{\circ} \mathrm{C}$ (a) and $500^{\circ} \mathrm{C}$ (c) in air, respectively, (b) and (d) the corresponding Tauc plots of $\mathrm{CuO}$ NWs films for the S1 and S2 samples.

\section{Temperature sensor fabrication}

Temperature sensors are widely used in our daily life. These devices can be used to control the environment temperature for human comfort. Temperature sensors can be used in many applications, including medical, semiconductor, automotive and food processing industries. Fig. 4a and
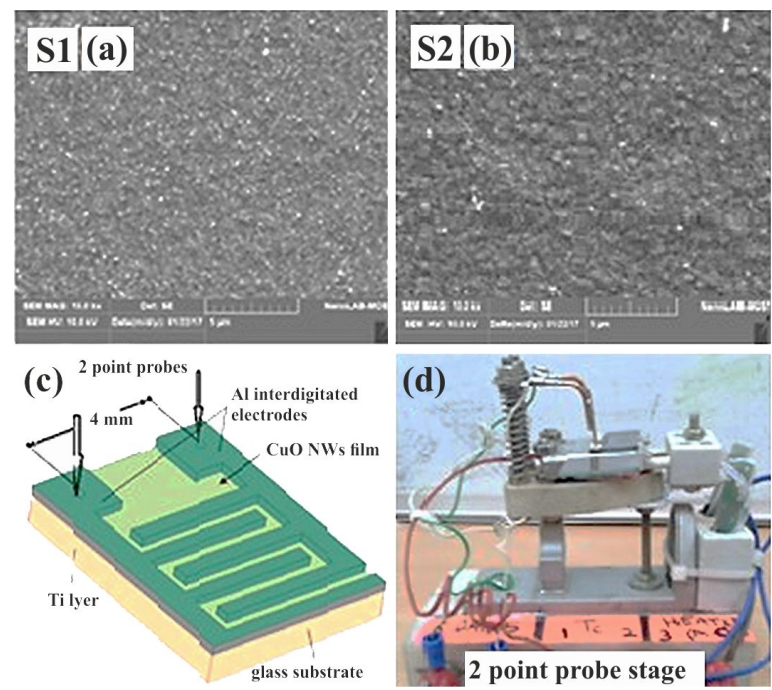

Fig. 4. SEM images of CuO NWs: (a) S1 and (b) S2, (c) schematic diagram of the temperature sensor, (d) homemade 2-point probe measurement stage.

Fig. 4b show the $\mathrm{CuO}$ films prepared at different oxidation temperatures $400{ }^{\circ} \mathrm{C}(\mathrm{S} 1)$ and $500{ }^{\circ} \mathrm{C}$ (S2), while Fig. 4c displays the temperature sensor device based on $\mathrm{CuO}$ film with aluminum interdigitated electrodes on the top. Experimental measurements were performed with a homemade two-point probe shown in Fig. 4d. 


\subsection{Electrical measurements}

Room-temperature I-V characteristics of $\mathrm{CuO}$ NWs on glass substrates prepared by oxidation method at $400{ }^{\circ} \mathrm{C}(\mathrm{S} 1)$ and $500{ }^{\circ} \mathrm{C}(\mathrm{S} 2)$ in air for $4 \mathrm{~h}$ are shown in Fig. 5. These curves exhibit ohmic behavior which results from the contact between $\mathrm{Al}$ interdigitated electrodes (Al-IDEs) and $\mathrm{CuO}$ NWs.

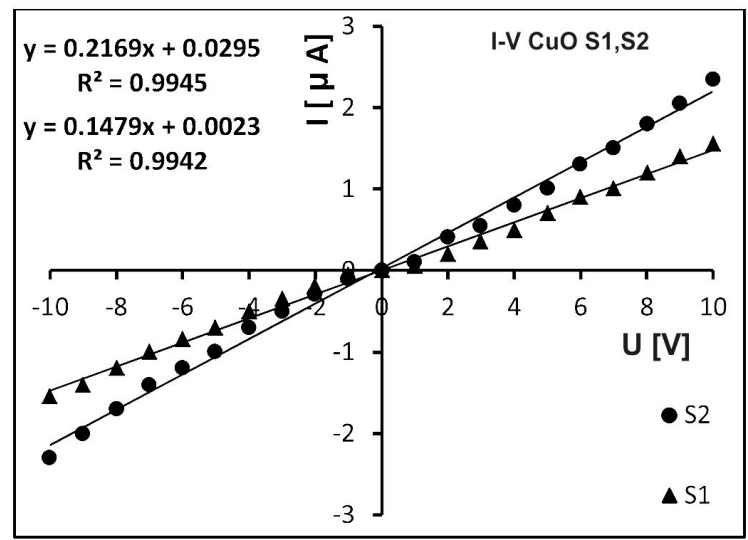

Fig. 5. I-V characteristics of $\mathrm{CuO} \mathrm{NWs}$ on glass for samples S1 and S2.

\subsection{Resistance variation dependent on temperature}

Fig. 6 illustrates the variation of $\mathrm{CuO}$ nanowires resistance with the environmental temperature. It is shown that the electrical resistance decreases from $6.9 \mathrm{M} \Omega$ to $0.76 \mathrm{M} \Omega$ for $\mathrm{S} 1$ and from 4.91 $\mathrm{M} \Omega$ to $0.52 \mathrm{M} \Omega$ for $\mathrm{S} 2$ sample as the environmental temperature increases from $20{ }^{\circ} \mathrm{C}$ to $180{ }^{\circ} \mathrm{C}$, which is confirmation of semiconducting behavior of these sensing materials. This behavior can be explained by the thermally activated mobility of the carriers [46] or by increase in the number of carriers at higher temperature [47]. Fig. 6 depicts also temperature dependence of the resistance of copper oxide films obtained at two oxidation temperatures. It appears that the electrical resistance of sample $\mathrm{S} 1$ is higher as compared to sample $\mathrm{S} 2$ due to its smaller crystallite size (as shown in Table 1). It is known that the resistance increases with the decreasing in the crystallite size, which leads to an increase of the grain boundaries number and subsequently increase in the carriers scattering on these boundaries [48].
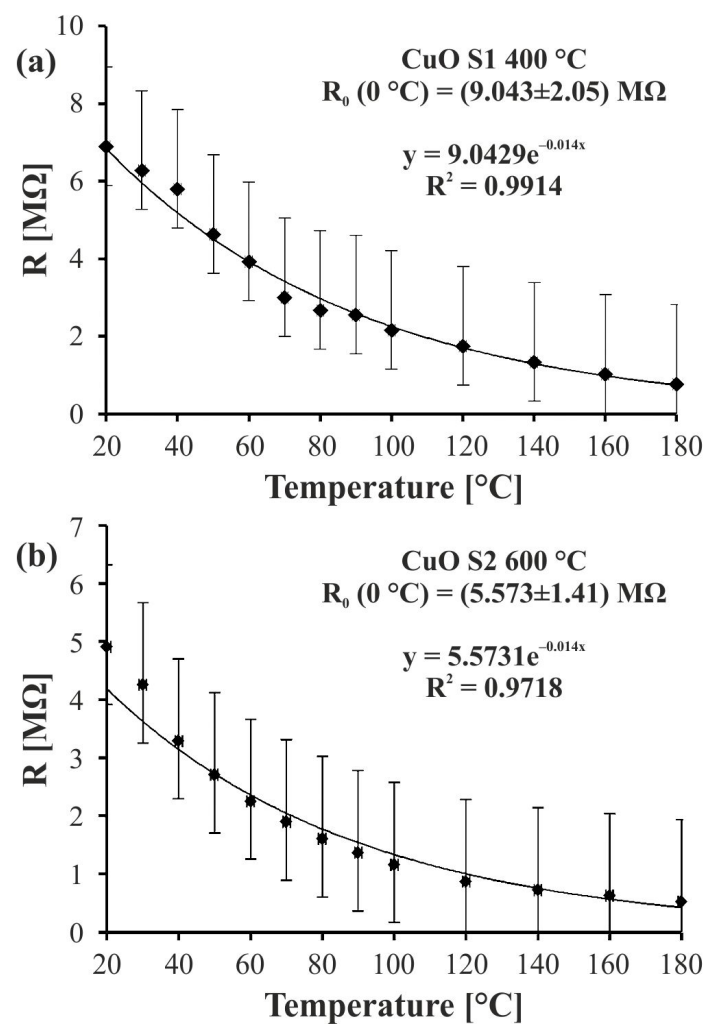

Fig. 6. Resistance vs. temperature for $\mathrm{CuO} \mathrm{NWs}$ on glass for S1 (a) and S2 (b).

\subsection{I-V Characteristics at various temper- atures}

The I-V characteristics of $\mathrm{CuO}$ NWs for $\mathrm{S} 1$ and S2 as a function of temperature in the range of $20{ }^{\circ} \mathrm{C}$ to $180{ }^{\circ} \mathrm{C}$ have been studied. The experimental data shown in Fig. 7 were fitted individually and show a linear relation: $\mathrm{Y}=\mathrm{mX}+\mathrm{a}$, where $\mathrm{m}$ is the slope, and a is a constant. The resistance for each curve can be calculated from the reciprocal of the slope.

To follow directly the resistance values of $\mathrm{CuO}$ NWs (S2), which were measured and drawn in Fig. 7 , the resistance $\mathrm{R}=$ (slope $^{-1}$ was evaluated as a function of temperature and drawn in Fig. 8. 

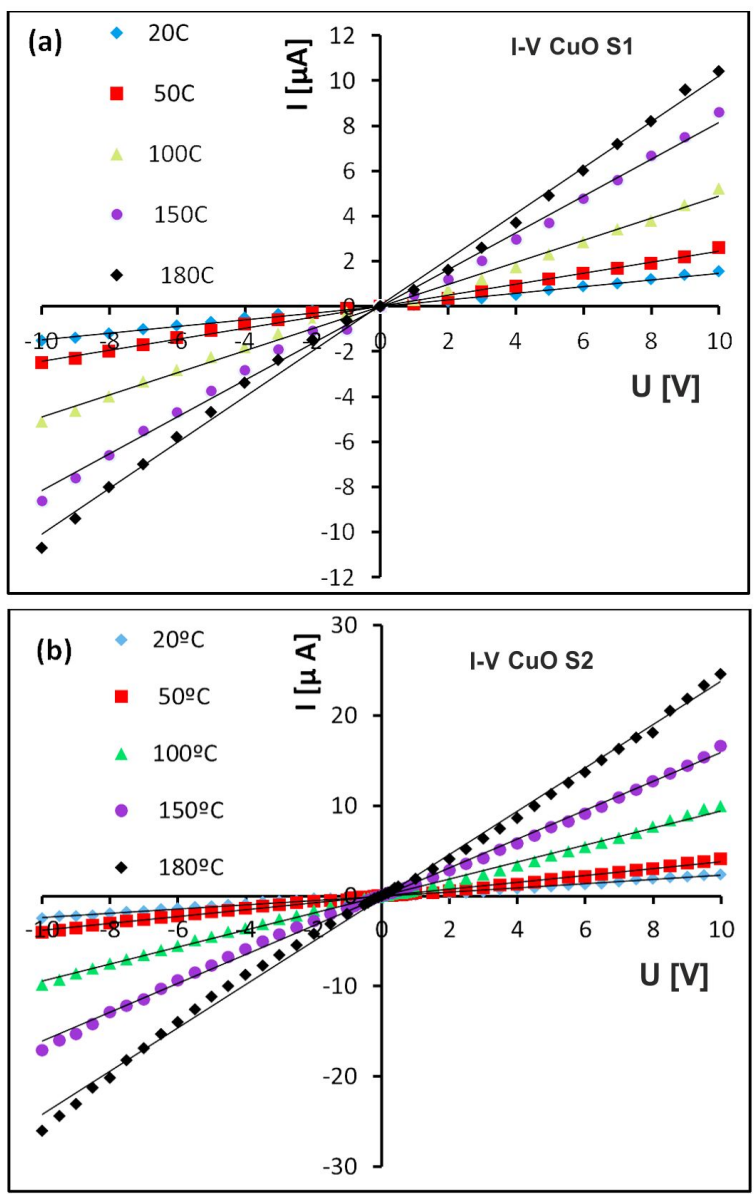

Fig. 7. I-V characteristics of $\mathrm{CuO} \mathrm{NWs}$ on glass for $\mathrm{S} 1$ (a) and S2 (b) samples at various temperatures.

\subsection{Electrical activation energy measure- ments}

To investigate the thermal conduction properties of $\mathrm{CuO} \mathrm{NWs}$ on glass substrate, the relation for semiconductor conductivity was used:

$$
\sigma=\sigma_{0} \exp \left(-E_{a} / k T\right)
$$

where $E_{a}, k, T$, and $\sigma_{0}$ are the activation energy, Boltzmann constant, temperature and proportionality constant, respectively. Equation 3 can be written as follows:

$$
\ln \sigma=\ln \sigma_{0}-\left(E_{a} / k T\right)
$$

The activation energies of $\mathrm{CuO} \mathrm{NWs}$ for $\mathrm{S} 1$ and $\mathrm{S} 2$ were determined as $0.158 \pm 0.004 \mathrm{eV}$ and $0.166 \pm 0.005 \mathrm{eV}$, respectively, by plotting $\ln \sigma$ versus $1000 / \mathrm{T}\left[\mathrm{K}^{-1}\right]$ as shown in Fig. 9. The activation energies are much smaller than the band gap energy which may indicate that the conduction is due to the transition of charge carriers from the valence band to the acceptor level [49].

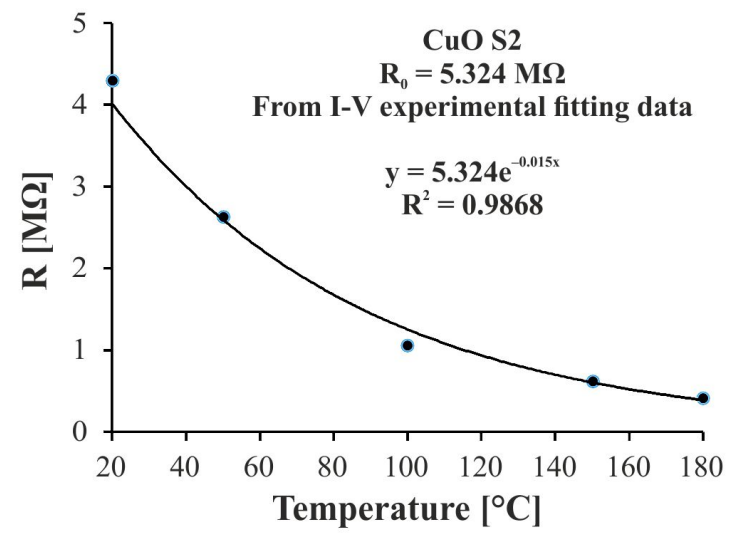

Fig. 8. Calculated resistance vs. temperature for $\mathrm{CuO}$ NWs (S2) on glass.

\subsection{Sensitivity of temperature sensor}

\subsubsection{Resistance response}

Fig. 10 shows the dependence of relative resistance on the temperature of sensing elements S1 and S2 which were made of copper oxide. The relative resistance of both samples decreases continuously with increasing temperature. $\mathrm{CuO}$ sensing elements $\mathrm{S} 1$ and $\mathrm{S} 2$ have the highest relative sensitivity (SR) to the temperature of $0.9 \pm 0.05 \% /{ }^{\circ} \mathrm{C}$ and $1.3 \pm 0.1 \% /{ }^{\circ} \mathrm{C}$, respectively, where the sensitivity of each sample has been determined from the slope of relative resistance vs. temperature. Such behavior can be attributed to increasing of electrical conductivity with increasing temperature due to electrons transition from the valence band to the conduction band. The average sensitivities (SA) for $\mathrm{S} 1$ and $\mathrm{S} 2$ samples were calculated to be $38.4 \pm 0.5 \mathrm{k} \Omega /{ }^{\circ} \mathrm{C}$ and $27.4 \pm 0.4 \mathrm{k} \Omega /{ }^{\circ} \mathrm{C}$, respectively. The relative sensitivity value recorded in this research is less than the reported value for pure copper oxide $\left(-5.2 \% /{ }^{\circ} \mathrm{C}\right)$ [17]. The relative sensitivity of typical semiconductor temperature sensors-thermistors is within a range of $-3 \% /{ }^{\circ} \mathrm{C}$ to $5 \% /{ }^{\circ} \mathrm{C}$ [18]. Finally, the activation energy and sensitivity data have been summarized in Table 2 . 
Table 2. Electrical parameters of $\mathrm{CuO}$ NWs on glass for $\mathrm{S} 1$ and $\mathrm{S} 2$ samples.

\begin{tabular}{cccc}
\hline $\begin{array}{c}\text { Relative sensitivity } \\
(\mathrm{SR})\end{array}$ & $\begin{array}{c}\text { Average sensitivity } \\
(\mathrm{SA})\end{array}$ & $\mathrm{Ea}[\mathrm{eV}]$ & $\begin{array}{c}\text { Sample No./oxidation } \\
\text { temp. }\left[{ }^{\circ} \mathrm{C}\right]\end{array}$ \\
\hline \hline $0.9 \pm 0.05 \% /{ }^{\circ} \mathrm{C}$ & $38.4 \pm 0.5 \mathrm{k} \Omega /{ }^{\circ} \mathrm{C}$ & $0.158 \pm 0.004$ & $\mathrm{~S} 1 / 400$ \\
$1.3 \pm 0.1 \% /{ }^{\circ} \mathrm{C}$ & $27.4 \pm 0.4 \mathrm{k} \Omega /{ }^{\circ} \mathrm{C}$ & $0.165 \pm 0.005$ & $\mathrm{~S} 2 / 600$ \\
\hline
\end{tabular}
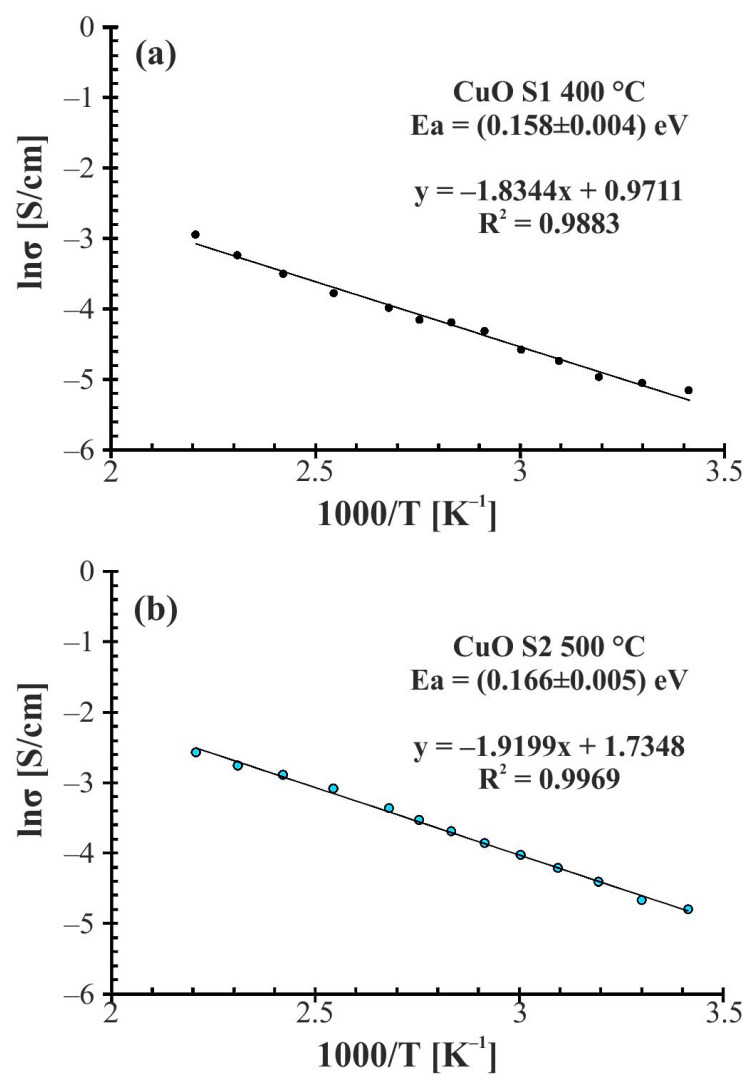

Fig. 9. $\ln \sigma$ vs. 1/T for CuO NWs on glass (a) $\mathrm{S} 1$ and (b) S2 sample.

\subsubsection{Current response}

The curves in Fig. 11 represent the current response of S2 sensor at bias voltages $5 \mathrm{~V}$ and $10 \mathrm{~V}$, which were collected from Fig. 7b. The high current response at the fixed bias voltages confirms the resistance variations, which were discussed previously. The sample of $\mathrm{CuO}$ NWs (S2) has a high current response and it can be used as a good gas sensor at high temperature and at fixed bias voltages of $5 \mathrm{~V}$ and $10 \mathrm{~V}$.

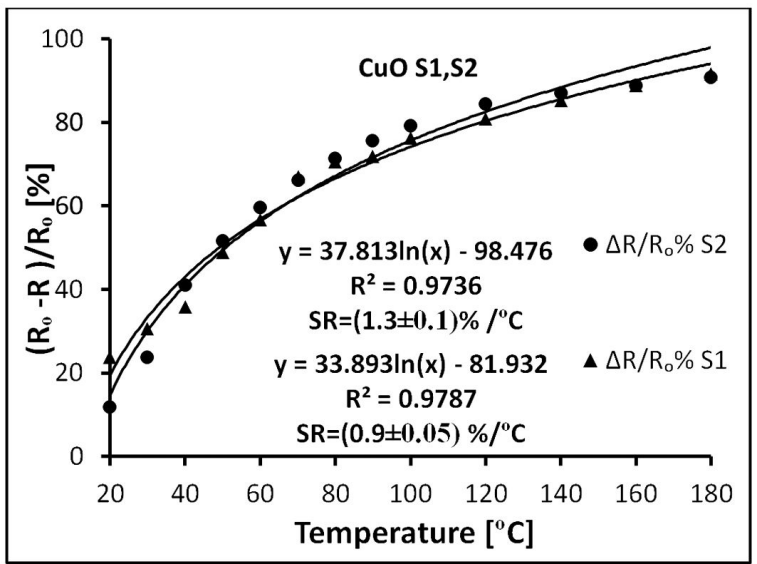

Fig. 10. Relative resistance variation vs. temperature for $\mathrm{CuONWs}$ on glass (a) $\mathrm{S} 1$ and (b) S2 sample.

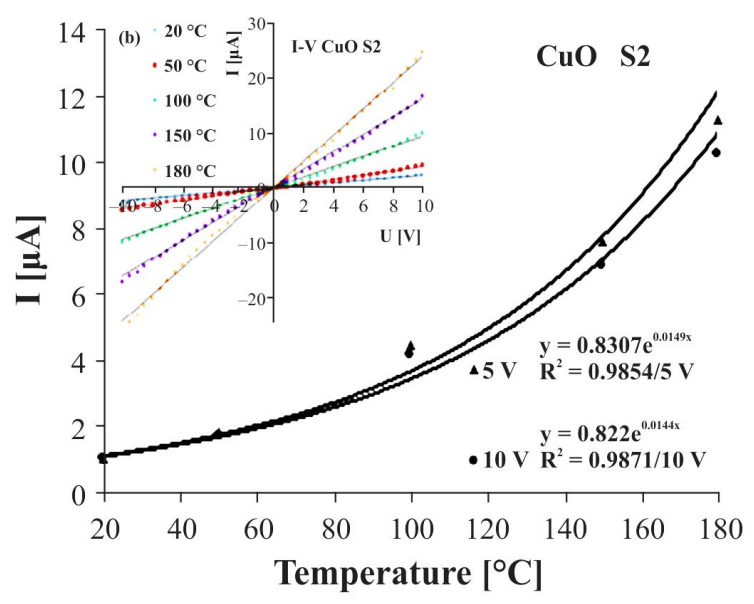

Fig. 11. Current vs. temperature at fixed bias voltages $(5 \mathrm{~V}$ and $10 \mathrm{~V})$ for $\mathrm{CuO}$ NWs (S2) on glass.

\section{Conclusions}

In conclusion, $\mathrm{CuO}$ nanowires were grown via oxidation method at different temperatures. The morphology and structure of the products were 
studied by SEM and XRD. The optical and electrical properties of prepared samples were investigated. From the optical properties of the $\mathrm{CuO}$ NWs, it is clear that the films reveal about $50 \%$ to $60 \%$ transmittance above $800 \mathrm{~nm}$ and the band gap energy increases with increasing oxidation temperature. The temperature sensing materials based on $\mathrm{CuO}$ nanowires exhibit high sensitivity and high current response and they can be used as a promising candidate for gas sensor and other electronic devices.

\section{References}

[1] Jayatissa A.H., Guo K., Jayasuriya A.C., Appl. Surf. Sci., 255 (2009), 9474.

[2] OoI P.K., NG S.S., Abdullah M.J., Hassan H.A., Hassan Z., Mater. Chem. Phys., 140 (2013), 243.

[3] Pham T.V., Rao M., Andreasson P., Peng Y., Wang J., Jinesh K.B., Appl. Phys Lett., 102 (2013), 032101.

[4] Necmi S., Tulay S., Seyda H., Yasemin C., Semicond. Sci. Tech., 20 (2005), 398.

[5] Ding T., Yang X., Bai L., Zhao Y., Fong K.E., WANG N., DeMIR H.V., Sun X.W., Org. Electron., 26 (2015), 245

[6] Chang T.H., Hsu C.Y., Lin H.C., Chang K.H., Li Y.Y., J. Alloy. Compd., 644 (2015), 324.

[7] Seongwan J., Young J.S., Sang H.J., Kang H.P., Catal. Commun., 81 (2016), 24.

[8] Li A., Song H., WAN W., Zhou J., Chen X., Electrochim. Acta., 132 (2014), 42.

[9] Khalida A., IKram U.H., Khan M., Powder Technol., 283 (2015), 505.

[10] Dahrul M., Alatas H., Irzaman, Procedia Environ. Sci., 33 (2016), 661.

[11] Vidyadharan B., Misnon I.I., Ismail J., YusofF M.M., R. Jose., J. Alloy. Compd., 633 (2015), 22.

[12] Jang J., Chung S., Kang H., Subramanian V., Thin Solid Films, 600 (2016), 157.

[13] Zhang Q., Zhang K., Xu D., Yang G., Huang H., Nie F., Liu C., Yang S., Prog. Mater. Sci., 60 (2014), 208.

[14] Zhao X., Wang P., Gao Y., Xu X., Xan Z., Ren N., Mater. Lett., 132 (2014), 409.

[15] Muhammad T.S.C., Khasan S.K., Sher B.K., ABDUllah M.A., Sensor. Actuat. A-Phys., 246 (2016), 58.

[16] Hsueh H.T., Hsueh T.J., Chang S.J., Hung F.Y., Tsai T.Y., Weng W.J., Hsu C.L., Dai B.T., Sensor. Actuat. B-Chem., 156 (2011), 906.

[17] Sher B.K., Muhammad T.S.C., Karimov K.S., Abdullha M.A., Mehran B., Rana T., Talanta, 120 (2014), 443.

[18] Robert B., Louis N., Electronic Devices and Circuit Theory, Prentice-Hall, New Jersey, 2006.
[19] Ma C., Zhu L., Chen S., Zhao Y., Mater. Lett., 108 (2013), 114

[20] Sahooli M., Sabbaghi S., SAboori R., J. Mater. Sci. Lett., 81 (2012), 169.

[21] Jia W., Reitz E., Shimpi P., Rodriguez E.G., Gao P.X., LEI Y., Mater. Res. Bull., 44 (2009), 1681.

[22] Mohamed R.M., Harraz F.A., Shawky A., Ceram. Int., 40 (2014), 2127.

[23] DAR M.A., Kim Y.S., Kim W.B., Sohn J.M., Shin H.S.J., Appl. Surf. Sci., 254 (2008), 7477.

[24] Ibupoto Z.H., Khun K., LU J., Willander M., Appl. Phys. Lett., 102 (2013), 103701.

[25] Mukherjee N., Show B., Maji S.K., Madhu U., Bhar S.K., Mitra B.C., Khan G.G., Mondal A. Mater. Lett., 65 (2011), 3248.

[26] Zhao J., LiU R., HuA Z., Superlattice. Microst., 81 (2015), 243

[27] Yu Q., Huang H., Chen R., Wang P., Yang H., Gao M., Peng X., Ye Z., Nanoscale, 4 (2012), 2613.

[28] Anandan S., LeE G., Wu J.J., Ultrason. Sonochem., 19 (2012), 682.

[29] Toboonsung B., Singuai P., J. Alloy. Compd., 509 (2011), 4132.

[30] Mallick P., Sahu S., Nanosci. Nanotechnol., 2 (2012), 71

[31] Lamrizeggara M., Ghabane L., AidA M.S., Attaf N., Zebbar N., Mater. Sci. Semicon. Proc., 30 (2015), 645

[32] Feng J.K., Xia H., Lai M.O., LU L., Mater. Res. Bull., 46 (2011), 424.

[33] Jung A., Cho S., Cho W., LeE K.-H., Korean J. Chem. Eng., 29 (2012), 243.

[34] Siddiqui H., QuREShi M.S., Haque F.Z., Int. J. Sci. Eng. Res., 5 (2014), 173.

[35] Zhu Y.F., Zhou G.H., LiN Y.B., LiU L., Cryst. Res. Technol., 47 (2012), 658.

[36] Chen A., Long H., Li X., Li Y., Yang G., LU P., Vacuum, 83 (2009), 927.

[37] Visalakshi S., Kannan R., Valanarasu S., Kathalingam A., Rajashabala S., J. Mater. Sci. Mater. El., 27 (2016), 9179.

[38] Goli M., Haratizadeh H., Abrishami M.E., Ceram. Int., 40 (2014), 16071.

[39] Mema R., Yuan L., Du Q., Wang Y., Zhou G., Chem. Phys. Lett., 512 (2011), 87.

[40] Yuan L., Wang Y., Mema R., Zhou G., Acta Mater., 59 (2011), 2491.

[41] Kim Y.S., Hwang I.S., Kim S.J., LeE C.Y., LeE J.H., Sensor. Actuat. B-Chem., 135 (2008), 298.

[42] William D.C., Materials Science and Engineering: An Introduction, John Wiley and Sons Inc., New York, 1997.

[43] Akaltun Y., ÇAYir, T., J. Alloy. Compd., 625 (2015), 144.

[44] Johan M.R., SUAn M.S.M., HaWARi N.L., ChInG H.A., Int. J. Electrochem. Sc., 6 (2011), 6094.

[45] Dodoo-Arhin D., Leoni M., SCARdi P., Mol. Cryst. Liq. Cryst., 555 (2012), 17. 
[46] SRIVAstava R., Int. J. Pure Appl. Sci. Technol., 14 (2013), 9.

[47] Cheng S.L., Chen M.F., Nanoscale Res. Lett., 7 (2012), 119.

[48] Orton J.W., Powell M.J., Rep. Prog. Phys., 43 (1980), 1263.
[49] Sisman O., Kilinc N., Ozturk Z.Z., Sensor. Actuat. B-Chem., 236 (2016), 1118.

Received 2017-07-24 Accepted 2018-04-24 